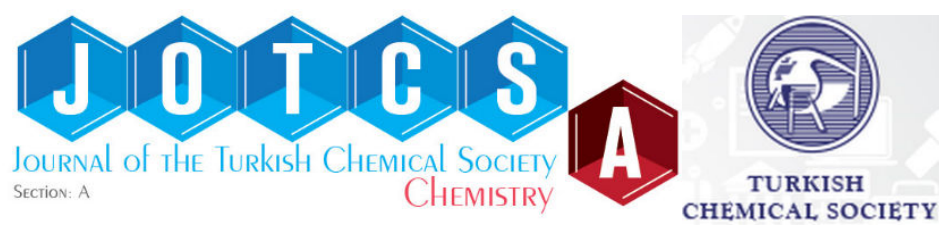

\title{
On the Systematics of Mass Spectrometry: A New Graph- Theoretical Method
}

\author{
Berkay Sütay*1 \\ ${ }^{1}$ Istanbul Technical University, Department of Chemistry, Istanbul, 34469, Turkey.
}

\begin{abstract}
The systematic background of mass spectrometry (MS) was established by using the Valency Interaction Formula theory in an efficient manner. A new graph theoretical method was developed as a pure quantum mechanical survey and applied on a variety of molecules and assemblies to elucidate the quantum mechanical systematics behind mass spectrometry. The topological indexes and graph theoretical methods in chemistry and physics as the striking features of this new method were applied onto the mass spectra of several molecules and assemblies due to the insufficiencies of the obsolete fragmentation procedures. These fundamental topological indexes were determined to make quick deductions pictorially on the mass spectra of molecules. The major fragmentation pathways for several molecules, as the striking features of Mass Spectometry, were examined in a pure theoretical way and a priori decomposition products were predicted. The systematic theory was provided in the light of our examination and a great deal of qualitative information was obtained just by knowing which interactions are soft among the others. The results are of general validity in comparison with the experimental data.
\end{abstract}

Keywords: Mass spectrometry; valency interaction formula; electron impact ionization; topology; graph theory.

Gönderme: 19 Ağustos 2016. İkinci tur: 20 Ekim 2016. Kabul: .09 Kasım 2016

Cite this: Sütay B. On the Systematics of Mass Spectrometry: A New Graph-Theoretical Method. JOTCSA. 2017;4(1):179-96.

DOI: To be assigned.

*Corresponding author. E-mail: sutay@itu.edu.tr. 


\section{INTRODUCTION}

Chemistry is a science that explains everything in the sense of molecular structures. This is the reason for a need in working with structural formulas by a pictorial language. Such a pictorial method allows the determination of the stabilities, reactivities, molecular properties and the strength of the bonding interactions, etc.; in an efficient manner. For this purpose, the Valency Interaction Formula (VIF) Theory is well enough to make such chemical deductions $(1,2)$ by supplying us with the very fundamental LPI (Level Pattern Indices) topological indexes as the direct number of bonding, nonbonding, and antibonding molecular orbitals (MO). The advantage of the VIF theory is that it enables a practical usage theoretically without requiring large scale computer calculations. It is possible to compare the bonding interactions as to their strengths and to find the soft interaction in the molecular structure which is required to explain the mass spectra in terms of the fragments.

Quantum Mechanics machinery was built on an abstract linear algebraic space -and also the linear operators- in terms of the superposition principle as a fundamental aspect (3). The eigenvectors of any Hermitian operator form a complete basis set which is also orthonormal. Then, a unitary transformation from such a complete basis set (4) to another becomes possible in the Hilbert space. Although these orthonormal basis sets have been used more often in quantum chemical computations, there is not a strict requirement for basis sets to be orthonormal. Even in many cases, the vectors of a basis set are not the eigenvectors of a physical observable. On the other hand, the orthonormal basis sets facilitate both algebraic and algorithmic convenience which may easily manifest itself by the well-known unity operator (I). In such a complete orthonormal basis of $\left\{\left|e_{i}\right\rangle\right\}$ ket vectors, this operator may be written as

$$
\mathrm{I}=\sum_{\mathrm{i} \geq 1}^{\infty}\left|\mathrm{e}_{\mathrm{i}}\right\rangle\left\langle\mathrm{e}_{\mathrm{i}}\right|
$$

where $\delta_{i j}=\left\langle e_{i} \mid e_{j}\right\rangle$. Then, the representation of an arbitrary operator (A) in this basis becomes $A=I A I$. For our particular interest into the molecular structure, one lets this operator be Hamiltonian $(\mathrm{H})$ and find Eq. 2.

$$
H=I H I=\sum_{i, j}\left|e_{i}\right\rangle\left\langle e_{i}|H| e_{j}\right\rangle\left\langle e_{j}\left|=\sum_{i, j} H_{i j}\right| e_{i}\right\rangle\left\langle e_{j}\right|
$$


However, the non-orthonormal basis sets are also used. These basis sets are the ones allowed by the superposition principle in a countably infinite dimensional linear vector space. Such a linear vector space is the Hilbert space (L2) which the quantum mechanics was built on rigorously by P.A.M. Dirac (3). The most general linear transformations on Hilbert space should include non-orthonormal bases. Mostly in Valence Bond (VB) theory, the atomic orbitals (AO) centered on the nuclei are not strictly orthogonal to each other which supports the overlaps $\left(S_{i j}=\left\langle e_{i} \mid e_{j}\right\rangle\right)$ and naturally the chemical bonding. In this particular case, VB and MO theories reflect very different formalisms, e.g. VB theory is based on the non-orthonormal bases and holds the chemist's intuitive structural picture of bonds and lone pairs while these localized orbitals remain lost in the MO picture. Both the expense of the nonorthogonality problem in VB theory and the plague of the delocalized orbitals of MO theory make it difficult to recover a pictorial language for chemists. The principle of linear covariance which was developed by Sinanoğlu $(1,2)$ unifies different formalisms of quantum chemistry (e.g. MO and VB formalisms), involves the largest group of transformations whether they are orthonormal or non-orthonormal and also leads to a comprehensive analysis of the higher symmetries of Hilbert space in the Euclidean space $\left(\varepsilon_{3}\right)$ in a very easy and elegant manner.

Principle of Linear Covariance: "The vectors, operators and their quantum mechanical equations are to be viewed as invariant under any linear transformations between different basis sets, in other words they should be linearly covariant in their tensor algebraic form." $(1,2)$.

On the basis of this principle, for a general non-orthonormal basis $\{\mid f i>\}$, Eq. 2 may be written in the tensorial form (5), Eq. 3.

$$
H=I H I=\left|f_{i}\right\rangle\left\langle f^{i}|H| f^{j}\right\rangle\left\langle f_{j}\left|=H^{i j}\right| f_{i}\right\rangle\left\langle f_{j}\left|\underline{\underline{\operatorname{orH}_{i j}}}\right| f^{i}\right\rangle\left\langle f^{j}\right|
$$

where $\mathrm{H}^{\mathrm{ij}}$ and $\mathrm{H}_{i j}$ are the contravariant and covariant components of Hamiltonian operator. In the sense of our chemical intuition, the one-electron Hilbert space requires to be projected onto the valency vector space $(V n)$ including the valence shell AOs. That means the Hilbert space for a molecule with $M$ number of atoms would be a tensor product of the one-electron Hilbert space L2(Ri) located at Ri $\in \varepsilon 3$, Eq. 4.

$$
\mathscr{L}_{2}(\overrightarrow{\mathrm{R}})=\mathscr{L}_{2}\left(\overrightarrow{\mathrm{R}}_{1}\right) \otimes \mathscr{L}_{2}\left(\overrightarrow{\mathrm{R}}_{2}\right) \otimes \ldots \ldots . \otimes \mathscr{L}_{2}\left(\overrightarrow{\mathrm{R}}_{M}\right)
$$


and the corresponding $V_{n}$ space of the molecular assembly as a direct sum,

$$
\mathrm{V}_{\mathrm{n}}(\overrightarrow{\mathrm{R}})=\mathrm{V}_{\mathrm{n}_{1}}\left(\overrightarrow{\mathrm{R}}_{1}\right) \oplus \mathrm{V}_{\mathrm{n}_{2}}\left(\overrightarrow{\mathrm{R}}_{2}\right) \oplus \ldots \ldots \oplus \mathrm{V}_{\mathrm{n}_{\mathrm{M}}}\left(\overrightarrow{\mathrm{R}}_{2}\right)
$$

In this projected valency vector space, the valency becomes 1 for $\mathrm{H}$ and $\mathrm{He}, 4$ for $\mathrm{Li}, \mathrm{Be}$, $\ldots, \mathrm{F}, \mathrm{Ne}$ and 9 for transition metals, etc., corresponding to $\{1 \mathrm{~s}\},\left\{2 \mathrm{~s}, 2 \mathrm{p}_{\mathrm{x}}, 2 \mathrm{p}_{\mathrm{y}}, 2 \mathrm{p}_{\mathrm{z}}\right\}$, $\left\{3 d_{x 2-y 2}, 3 d_{z 2}, 3 d_{x y}, 3 d_{x z}, 3 d_{y z}, 4 s, 4 p_{x}, 4 p_{y}, 4 p_{z}\right\}$ respectively, and so on. Thus, each atom is represented by a graph which is called a VIF picture (1) as in Fig. 1.

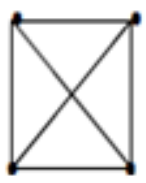

\section{$\mathrm{H}$ and $\mathrm{He}$}

$\mathrm{Li}, \mathrm{Be}, \mathrm{B}, \ldots . . ., \mathrm{F}, \mathrm{Ne}$

Figure 1. The graph representations of $1^{\text {st }}$ and $2^{\text {nd }}$ row elements as their VIF pictures.

In these graphs which reflect the topology of the molecular assembly in Hilbert space as a projection into Euclidean space, $\mathrm{H}_{\mathrm{ij}}$ tensor components (matrix elements) correspond to the strengths of the bonding interaction between the nearest-neighbour atomic orbitals. For the sake of simplicity, these $H_{i j}$ values are assumed to be the same and taken as unity.

Hitherto, one may conclude that the unity operator (I) projects the full Hilbert space onto the valency shell space $V_{n} C L_{2}$ and depicts the molecular structure in Euclidean space which leaves a very practical tool for chemists and keeps their chemical intuition alive. This VIF theory overcomes the insufficiencies of previous approaches in the area of chemical graph theory (6-9) and other topological treatments by giving the direct LPI of any molecule in a very easy way.

Every molecule is represented by a VIF structure which depicts the one-electron interactions given in one-electron hamiltonian $(\mathrm{h})$. For any molecule made up of main group elements with the valency shell size $n=4$, the four atomic orbitals ( $s$ and $p$ valencies only) are joined to each other and therefore each atom appears as a tetrahedron, and combining the neighboring tetrahedra leads to the VIF pictures. The two following pictorial rules are applied to these VIF structures: 
Rule 1: A valency point may be multiplied by a nonzero constant $(\kappa)$ which can be positive or negative (Multiplication rule).

Rule 2: A valency point may be superimposed on another valency point bringing its valency interactions with it (Addition rule).

These rules may be applied any number of times, in any desired combination until the VIF is fully reduced by eliminating the non-nearest neighbour interaction lines, at last one reads off the LPI from the final picture; $\left\{n_{+}, n_{0}, n_{-}\right\}$. The number of free dots giving the number of nonbonding MOs and each single interaction line indicates the presence of a pair of bonding and antibonding MOs. Finally the electrons are assigned to the MOs to get the Electron Count Index (ECI); $\left\{\mathrm{N}_{+}, \mathrm{N}_{0}, \mathrm{~N}_{-}\right\}$. A simple example illustrates the rules and their use in Fig. 2.

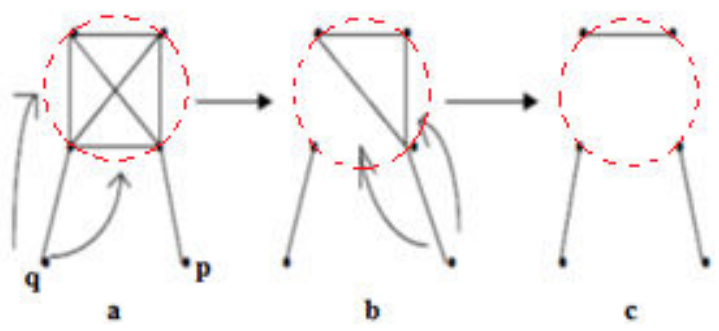

Figure 2. The reduction of the VIF picture for water molecule. a. Point $q$ is multiplied by -1 , then the line ended with point q gains -1 strength and superimposed onto three neighbouring lines with initial strength 1 . b. The same is applied to point p. c. Finally only three lines of the initial eight remain free. This final reduced-VIF corresponds to $\mathrm{LPI}=\{3,0,3\}$ as indicated in (9).

Recently, VIF theory was applied to copper clusters and iron(II)-oxygen bonding in hemoglobin molecule via one-electron density operator version of the theory $(10,11)$.

In view of this theory, we will deal with a number of examples by predicting the decomposition products (fragments) before getting a mass spectrum data, each providing a systematical approach. The obselete fragmentation procedures are only capable of dealing with small molecules and hard to perform in making quick a priori deductions. The previously developed topological indices and graph theoretical methods on the molecular structure are also insufficient and none of these methods could explain the mass spectra of molecules.

There are several different ways to ionize a sample in mass spectrometry from electron impact to electron spray or chemical ionization displaying different fragmentation products. Each of these methods has its own disadvantages, e.g. in the case of the most 
commonly used electron impact ionization, the molecule must be volatile, thermally stable and its extensive fragmentation -due to the hard ionization process- beclouds the selection of important peaks among the others most of which correspond to many unnecessary second generation product ions. There is not even a method or theory in dealing with the mass spectra purely. Now, it can be possible that knowing an a priori mass spectrum of any molecule by using our new method in the present paper. The most important advantage of this new method is its highly user-friendly character, without requiring to know the mathematics behind the method essentially and lets us get a priori predictions on the fragments, even for very large or complex molecules. It is applicable to any molecule without considering its thermal stability under the conditions of "electron impact (EI) ionization" procedure. The second important advantage of this method is about the direct determination of the first generation fragments (e.g. positively charged molecular ions) which supplies an easy picking of the useful peaks and leaving several unimportant peaks directly eliminated.

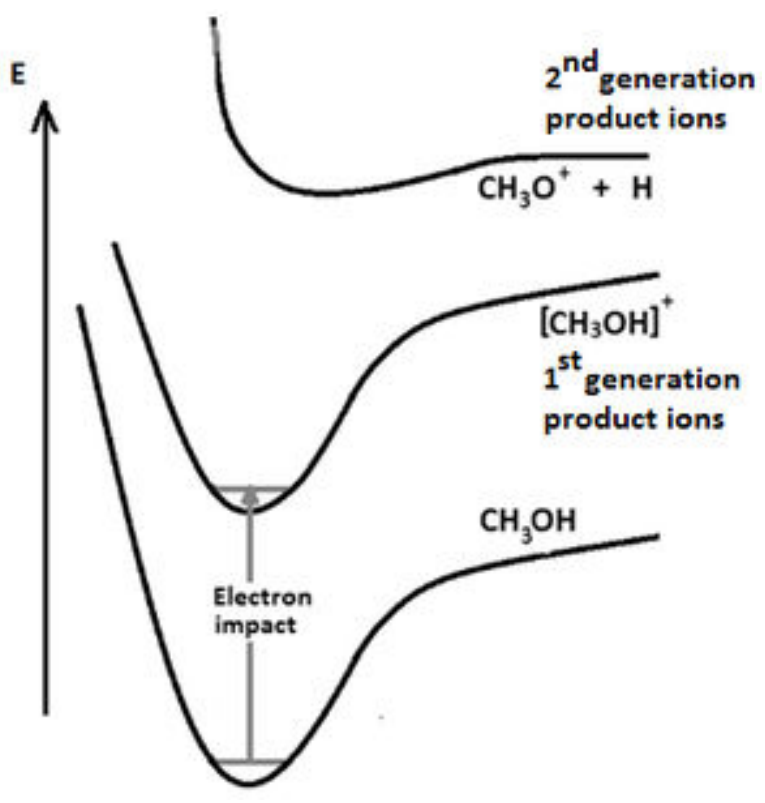

Figure 3. The potential energy change in methanol molecule after electron impact treatment (12).

The fragmentation in electron ionization can be described using potential curves as in the diagram. The electron impact energy is enough to remove an electron from the analyte and form a molecular ion (see Figure 3). The standard electron ionization source to induce analyte ionization is about 70 electron volt (eV) electrons, but this level of energy is so much higher than the energy required for ionization of most common compounds (typically between 6 and $12 \mathrm{eV}$ ). Most of the excess energy is dissipated via vibroelectronic excitation modes. Due to the higher energy supplied by $70 \mathrm{eV}$ accelerated electrons, several other bond dissociation reactions become possible which produce 
second generation product ions by breaking the stronger bonds in the molecule. In the case of methanol, the molecular ion is formed after the electron impact treatment, but second generation fragments $\left(\mathrm{CH}_{3} \mathrm{O}^{+}\right)$starts forming at higher levels of energy through $70 \mathrm{eV}$. The VIF picture of methanol molecule was shown in Table 1.

Table 1. VIF picture of methanol molecule.

VIF picture

It is clear to see that all $\mathrm{C}-\mathrm{H}, \mathrm{C}-\mathrm{O}$ and $\mathrm{O}-\mathrm{H}$ bonds survive after the reduction of VIF picture. This verifies the first generation product as $\mathrm{CH}_{3} \mathrm{OH}^{+}$molecular ion in its mass spectrum, Figure 4.
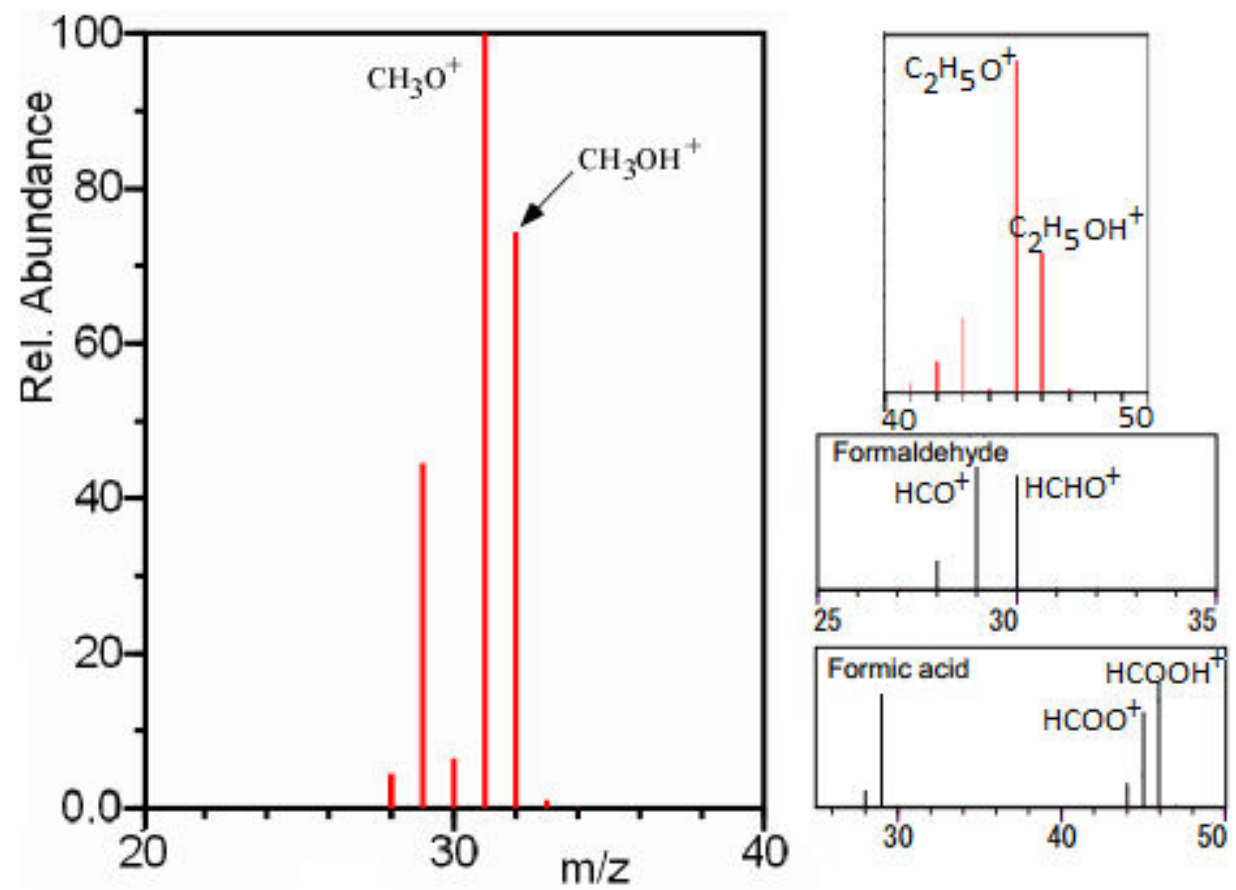

Figure 4. Mass spectra of methanol, ethanol, formaldehyde, and formic acid (15).

A similar situation may also be seen in the mass spectra of ethanol, formaldehyde, and formic acid molecules which produce their molecular ions as well. Then, $\mathrm{CH}_{3} \mathrm{O}^{+}, \mathrm{C}_{2} \mathrm{H}_{5} \mathrm{O}^{+}$, $\mathrm{HCO}^{+}$and $\mathrm{HCOO}^{+}$ions (one hydrogen losing) in the given spectra remain as the secondary products. The higher dissociation energy of $\mathrm{CH}_{3} \mathrm{O}-\mathrm{H}$ bond $\left(440 \mathrm{~kJ}^{-\mathrm{mol}^{-1}}\right)$ in methanol molecule (16) along with the VIF reduction argument leaves those ions as the second generation ones. The solid localized orbital scheme of methanol (9) and its water 
molecule analogy with methyl linkage (1) also verify this argument, in other words, any weak bond interaction in these systems does not exist. To clarify this argument and relate it to mass spectrometry, it is necessary to go one step further in terms of looking for the weaker or softer interactions inside a molecule.

In Fig. 5, several well-known explosive molecules were shown.<smiles>O=[N+]([O-])c1cc([N+](=O)[O-])cc([N+](=O)[O-])c1</smiles>

TNB<smiles>Cc1ccc([N+](=O)[O-])cc1N</smiles>

MNA<smiles>O=[N+]([O-])c1nc([N+](=O)[O-])nc([N+](=O)[O-])n1</smiles>

TNTA<smiles>Cc1c([N+](=O)[O-])cc([N+](=O)[O-])cc1[N+](=O)[O-]</smiles>

TNT

Figure 5. Structures of several well-known explosives (TNB: trinitrobenzene, MNA: methylnitroaniline, TNTA: trinitrotriazine, TNT: trinitrotoluene).

Various DFT computations (17-20) along with AIM analysis on several well-known expulsive molecules predicted that the significantly low $\mathrm{C}-\mathrm{NO}_{2}$ bond electron density $\left(\sim 1.76-1.83 \mathrm{e} / \AA^{3}\right)$ as well as its Laplacian $\left(\sim-17 \mathrm{e} / \AA^{5}\right)$ indicate highly charge depletion (very low charge accumulation) in this bond in comparison to other bonds in the molecules (see Table 2). All those confirm that $\mathrm{C}-\mathrm{NO}_{2}$ bonds are the weakest linkages in the molecule.

Table 2. Topological properties of $\mathrm{C}-\mathrm{NO}_{2}$ bond in various explosives.

\begin{tabular}{|l|c|c|}
\hline & $\boldsymbol{\rho}\left[\mathbf{e} / \AA^{\mathbf{3}}\right]$ & $\begin{array}{c}\boldsymbol{\nabla}^{\mathbf{2}} \mathbf{p} \\
{\left[\mathbf{e} / \AA^{\mathbf{5}}\right]}\end{array}$ \\
\hline TNB $^{\mathrm{a}}$ & 1.77 & -16.7 \\
\hline MNA $^{\mathrm{b}}$ & 1.76 & -16.4 \\
\hline TNTA $^{\mathrm{c}}$ & 1.83 & -18.3 \\
\hline TNT $^{\mathrm{d}}$ & 1.78 & -17.1 \\
\hline
\end{tabular}

(a. ref.17, b. ref.18, c. ref.19, d. ref.20.)

Table 2 also supports the transferability of these two topological properties between highly similar molecules, e.g. the same values may be assigned to $\mathrm{C}-\mathrm{N}$ bonds in nitrobenzene (NB) and dinitrobenzene (DNB) which only differs in the number of nitro groups from TNB. On the other hand, the trend in the change of Laplacian of bond electron densities for all bonds in TNB molecule was drastically decreased in three $\mathrm{C}-\mathrm{NO}_{2}$ bond regions (17). That situation indicates another realistic bond sensitivity in the molecule, whereas the other bonds does not exhibit this kind of relationship (In the present work, this sensitive bonds will be called as soft interactions). The VIF picture of nitrobenzene (NB) molecule was shown in Table 3. 
Table 3. VIF picture of NB molecule.

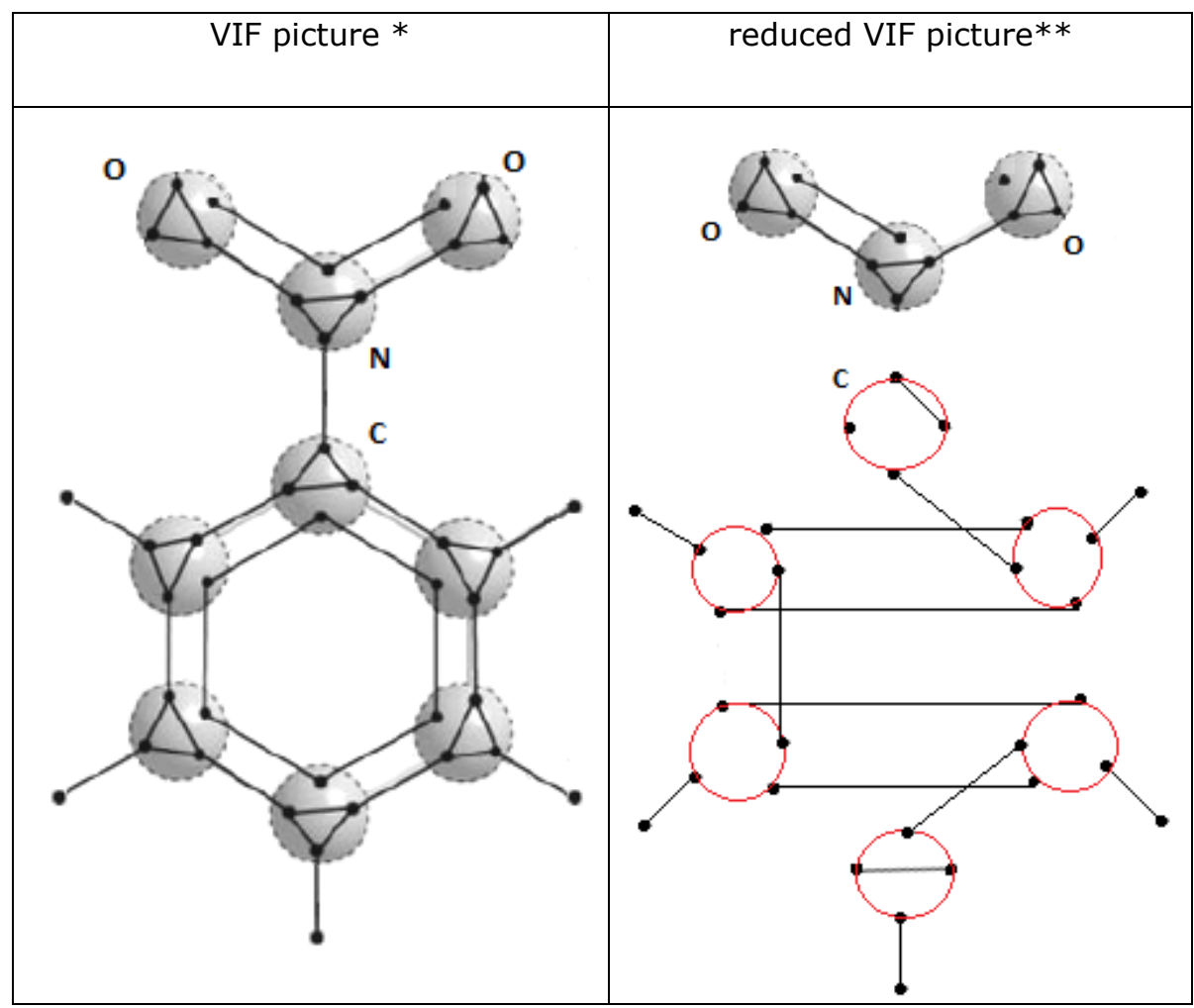

(* pi resonance of nitro group with benzene cloud was not shown ** for reduction, please see appendix)

It may be already seen that $\mathrm{C}-\mathrm{N}$ bond line has vanished which makes it a soft interaction in NB molecule $\left(M=123 \mathrm{~g} \cdot \mathrm{mol}^{-1}\right)$. This result verifies the topological argument above for the weakness of $\mathrm{C}-\mathrm{N}$ bond above. Then it is expected to observe $\mathrm{m} / \mathrm{z}=77$ peak in its mass spectrum due to the loss of nitro group, (see Figure 6).
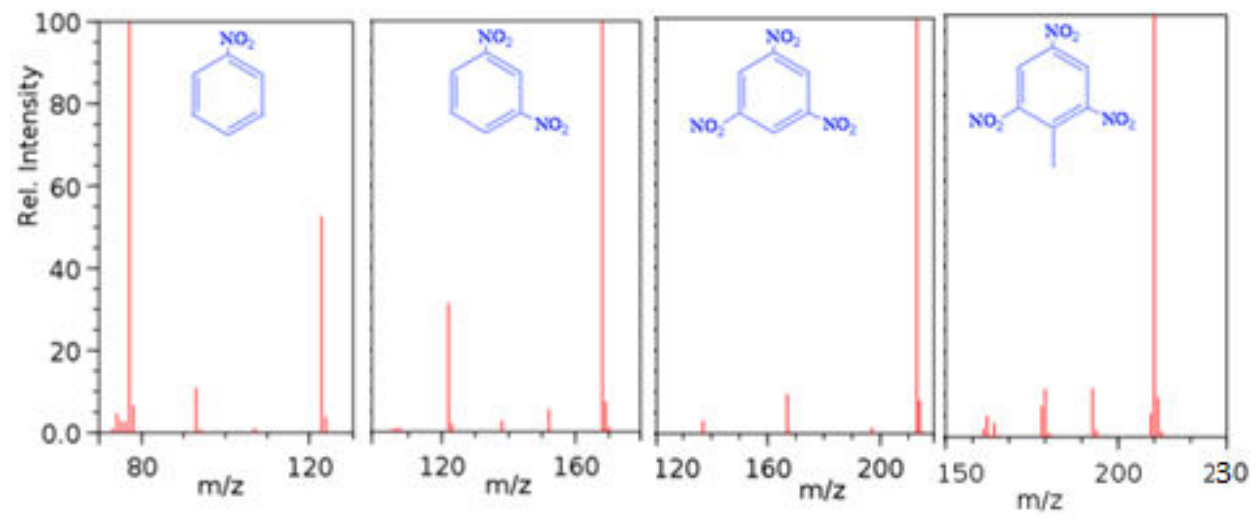

Figure 6. Mass spectra of NB, DNB, TNB and TNT (15).

The validity of the same argument was also clear in the mass spectra of DNB (168 g.mol$\left.{ }^{1}\right)$, TNB (213 g.mol$\left.{ }^{-1}\right)$ and TNT (227 g.mol ${ }^{-1}$ ) molecules, each of those has $\mathrm{m} / \mathrm{z}=122,167$ and 181 peaks in their spectra respectively. 


\section{Applications}

First, we will handle the mass spectrum of a general hydrocarbon, consisting of $\mathrm{C}-\mathrm{H}$ and $\mathrm{C}-\mathrm{C}$ bonds only. Since there are no heteroatoms in a hydrocarbon molecule, there are no nonbonding MOs and nonbonding valence shell electrons as well. Consequently, the cationic character of a hydrocarbon molecular ion is delocalized over all the bonds. We may also deduce that, from the full-reduced VIF picture in Table 4, there is no soft interaction between any two atoms; therefore there is no specific cleavage region in the molecule (the wiggly line indicates the long carbon chain).

Table 4. VIF pictures for a general hydrocarbon.

General VIF picture

The $\mathrm{C}-\mathrm{C}$ bonds are weaker than $\mathrm{C}-\mathrm{H}$ bonds and thus, we except the fragmentation of $\mathrm{C}-\mathrm{C}$ bonds that causes producing of a mixture of alkyl carbocations, easily seen in the mass spectrum of any hydrocarbon. All these significant fragment ions, the corresponding carbocations, are $\mathrm{CH}_{3}{ }^{+}(\mathrm{m} / \mathrm{z}=15), \mathrm{C}_{2} \mathrm{H}_{5}{ }^{+}(\mathrm{m} / \mathrm{z}=29), \mathrm{C}_{3} \mathrm{H}_{7}{ }^{+}(\mathrm{m} / \mathrm{z}=43), \mathrm{C}_{4} \mathrm{H}_{9}{ }^{+}(\mathrm{m} / \mathrm{z}=57)$; etc. One can see the corresponding peaks in Figure 7 , as a model spectrum.

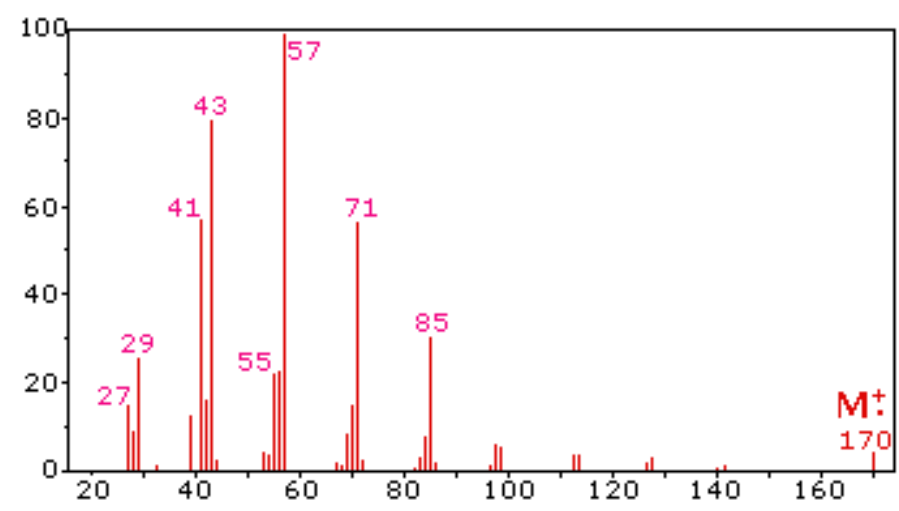

Figure 7. The mass spectrum of dodecane molecule (21).

Another group of compounds is oximes. An oxime molecule has a variety of bonds with different polarity and different strengths; such as C-H, C-N, C-C, C-O, etc. It seems a bit difficult and complicated to determine the possible cleavage regions for oximes, but now, it is possible to deduce the decomposition products by using the VIF theory. The VIF picture for a general oxime molecule is given in Table 5 . 
Table 5. The VIF pictures for a general oxime molecule.

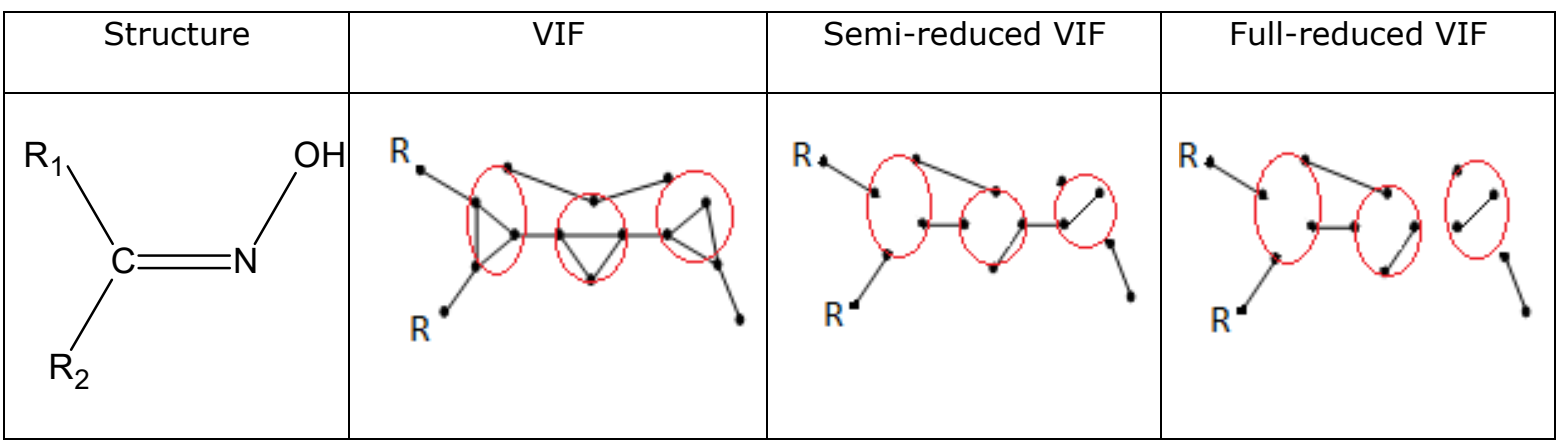

One may get the result that the intraatomic interaction lines of nitrogen and oxygen tend to decompose the $\mathrm{N}-\mathrm{O}$ bond; in other words, the $\mathrm{N}-\mathrm{O}$ interaction is the soft one among the other heteronuclear bonds. By this way, N-O interaction line does not appear in the full-reduced VIF which means, an oxime molecule always decomposes by the cleavage of a $\mathrm{N}-\mathrm{O}$ bond (Figure 8 ).

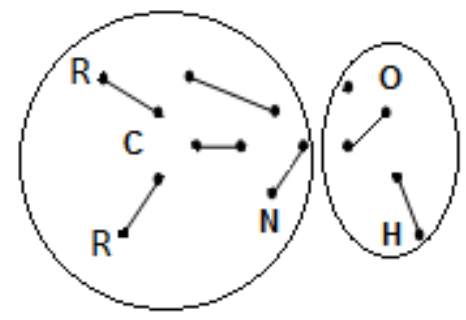

Figure 8. Fragments of a typical oxime molecule. The cleavage of $\mathrm{N}-\mathrm{O}$ bond was clearly shown.

Thus, we get two main fragments; one of which is always hydroxyl $\left(\mathrm{OH}^{-}\right)$ion, corresponding peak having the $\mathrm{m} / \mathrm{z}$ value 17 , and the other is the remaining part. These two fragments, as two major peaks, exist in the mass spectra of all oximes, Fig. 9. 


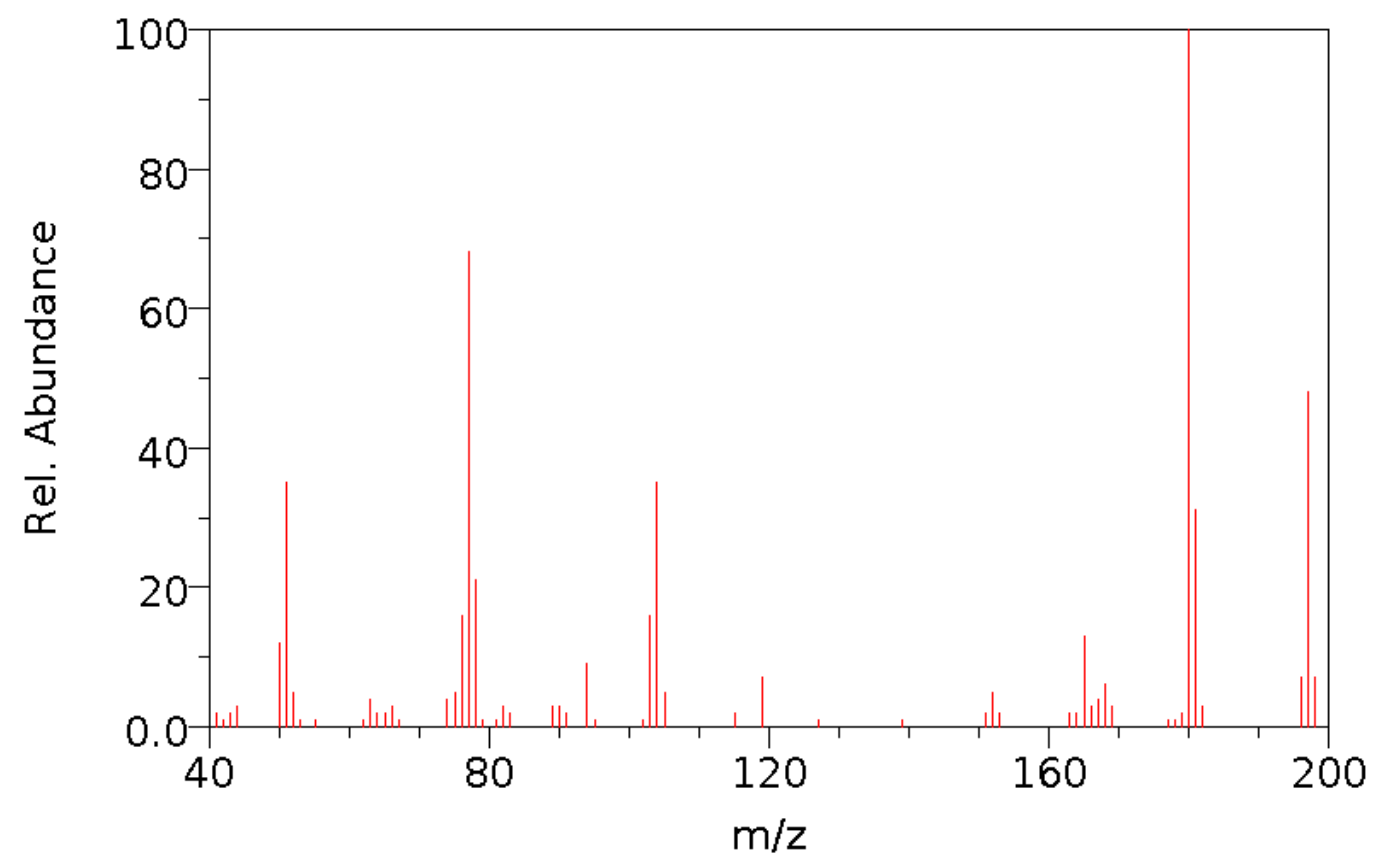

Figure 9. The mass spectrum of methanone, diphenyl-, oxime $(M=197)$ molecule. The M-17 peak was not showed in the spectrum (21).

The spectrum of the oxime shows an appreciable $M-180$ peak indicating that it is mainly due to loss of the hydroxyl group with a remaining part as a second fragment. Of course, if there is a oxygen-substituted oxime molecule, e.g. for $-\mathrm{OCH}_{3}$, there will be a $\mathrm{m} / \mathrm{z}=31$ peak instead of $m / z=17$, the cleavage of the $\mathrm{N}-\mathrm{O}$ bond still holds.

Our final interest is Schiff bases which have different kind of bonds than the oxime molecules. Likewise, it is a bit complicated to estimate the fragments of the Schiff bases in their mass spectra. We will use the VIF theory again to determine the decomposition products in a completely theoretical approach. The VIF picture for a general Schiff base is given in Table 6.

Table 6. The VIF pictures for a general Schiff base molecule.

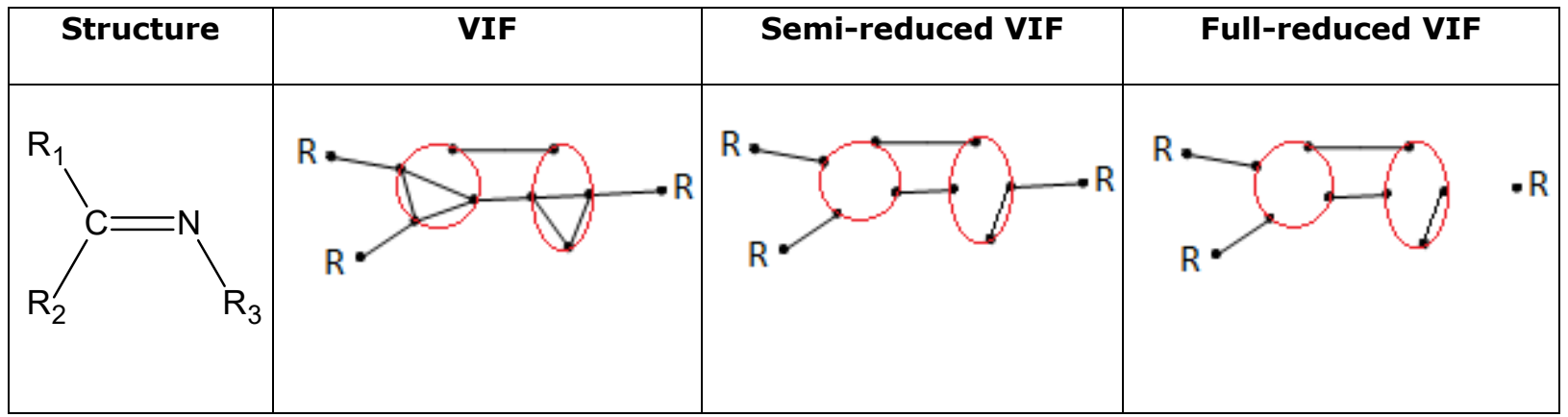

The semi-reduced VIF indicates the cleavage of the $\mathrm{C}-\mathrm{N}$ bond, from the amine side of the molecule, by the intraatomic interaction line of nitrogen atom, in other words, this $\mathrm{C}-\mathrm{N}$ 
interaction is soft, which is also implicit in the full-reduced VIF picture. Consequently, a Schiff base molecule tends to be divided into two main parts by the cleavage of this bond. These two main fragments exist in the mass spectra of all Schiff base molecules as two major peaks. For example, these two fragments for the molecule given below can be deduced readily in the light of a recent study (22);
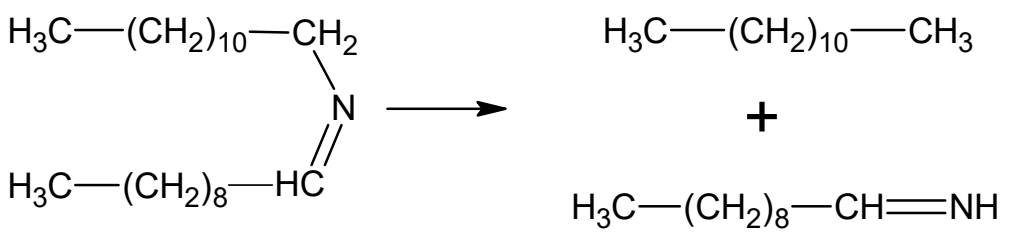

the $\mathrm{m} / \mathrm{z}$ values are 170 and 156 for (1) and (2) fragments respectively. These two major peaks can easily be seen in the mass spectra of this Schiff base in Fig. 10.

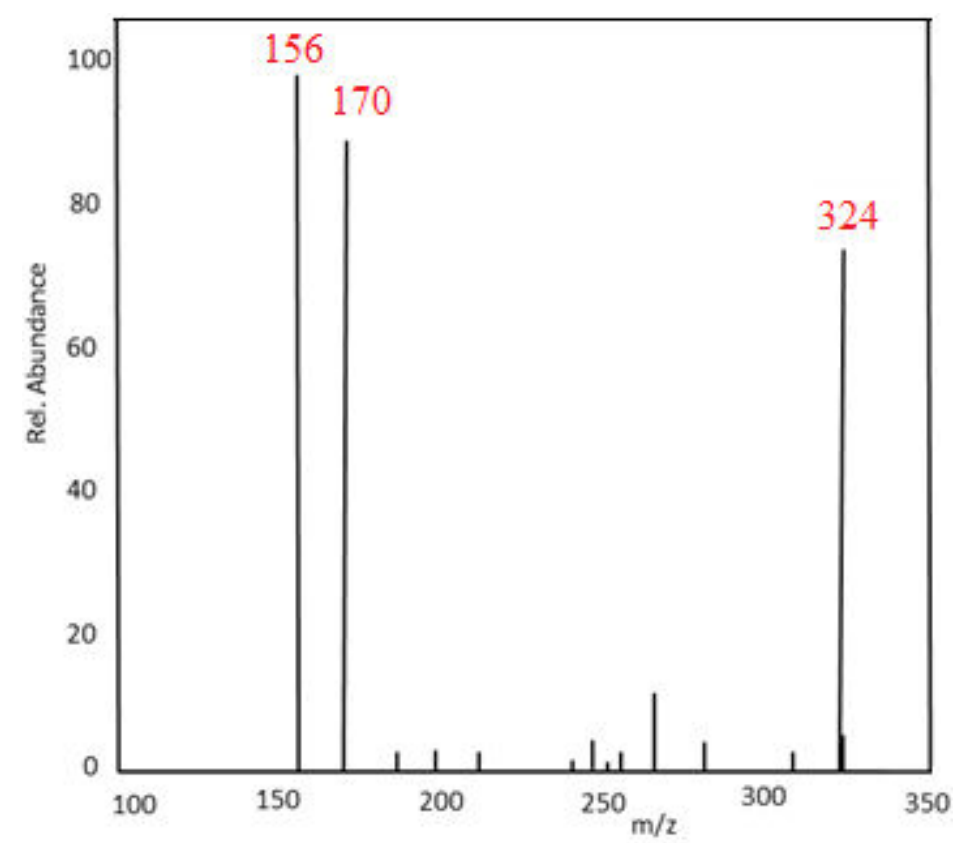

Figure 10. The mass spectrum of the Schiff base molecule (22).

One may increase the number of the examples even further(23-25); but we want to end this argument with a comprehensive example; the mass spectrum of a 2-substituted cyclohexanone oxime which is worthwhile to examine. Table 7 shows the molecule and its VIF picture (the wiggly lines indicate the remaining parts of the molecule, we only used the necessary parts). 
Table 7. A somewhat simplified VIF pictures of the 2-substituted oxime molecule.

Structure Clarified $\mathrm{VIF}$

We see that, from the semi-reduced-VIF, there are three main segments; chlorine $(m / z=35)$, hydroxyl group $(m / z=17)$, and the final segment which is due to the loss of the hydroxyl group, namely the remaining part $(m / z=218)$.

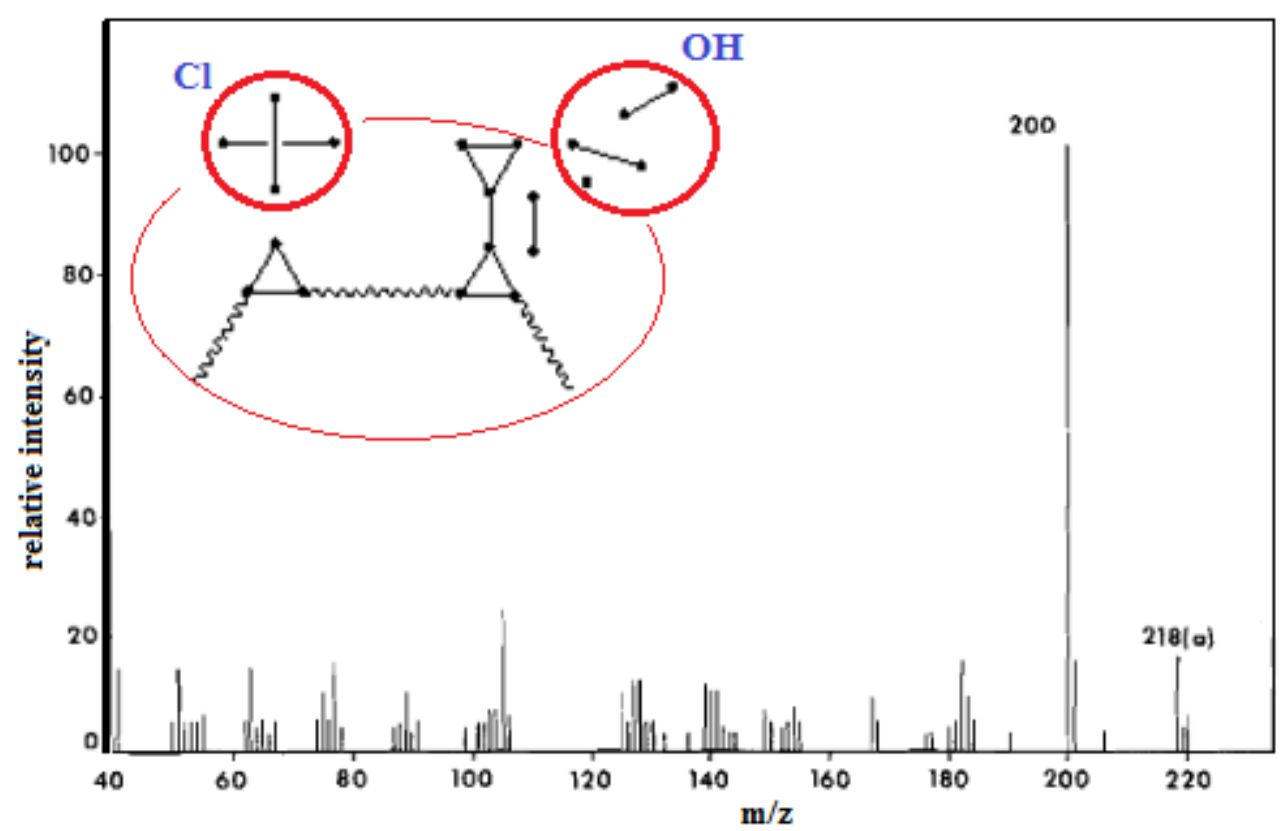

Figure 11. The mass spectrum of the oxime molecule from Table $7(23) .(m / z=17$ and 35 peaks are not available in the experimental spectrum in which $\mathrm{m} / \mathrm{z}$ axis starts from value 40).

These peaks have major importance and may easily be seen in the mass spectrum (see Figure 11) (23).

Conclusion. A new approach was presented in this paper for the development of the systematics of mass spectrometry in the sense of modern quantum mechanical methods. This aforementioned method was quite simplified and one may easily quickly manipulate 
this method for the quick predictions of a priori mass spectra. It is also possible that we may get the main fragmentation results in the generalized form for a given compound family as to type of their bonding characteristics; like we have shown in this paper. Such an a priori work will also be helpful for enlightening the characterization of newly synthesized molecules.

\section{REFERENCES}

1. Sinanoğlu $\mathrm{O}$. New method for qualitative quantum chemical deductions on organic or inorganic molecules or clusters directly from structural formulas or ORTEP diagrams. Theoretica Chimica Acta. 1985 Oct;68(4):251-70.

2. Sinanoğlu $\mathrm{O}$. A theorem for qualitative deductions in organic or inorganic chemistry regarding the relative stabilities, distortions and reactions of molecules. Chemical Physics Letters. 1984; 103, 315.

3. Dirac PAM. The principles of quantum mechanics. 4. ed. (rev.), repr. Oxford: Clarendon Press; 2009. 314 p. (The international series of monographs on physics).

4. Courant R, Hilbert D. Methods of mathematical physics. New York: Interscience Publishers; 1989. 2 p. (Wiley classics library).

5. Schultz-Piszachich, W., Tensor Algebra Analysis, 4th ed., Teubner, Leipzig (1988).

6. King, R.B., eds., Chemical Applications of Topology and Graph Theory, Elsevier (1983).

King RB, United States, editors. Chemical applications of topology and graph theory: a collection of papers from a symposium held at the University of Georgia, Athens, Georgia, U.S.A., 18-22 April 1983. Amsterdam; New York: Elsevier; 1983. 494 p. (Studies in physical and theoretical chemistry).

7. Bonchev D, Rouvray DH, editors. Chemical graph theory: introduction and fundamentals. New York: Abacus Press; 1991. 288 p. (Mathematical chemistry).

8. Balaban AT, editor. Chemical applications of graph theory. London; New York: Academic Press; 1976. $389 \mathrm{p}$.

9. Sinanoglu O, Alia J, Hastings M. Valency Interactions in AHm0,--+. (Hydrides of Main Group Elements, Radicals, Cations, Anions) and MO Energy Level Patterns Directly from the Pictorial "VIF" Method Compared with Computer Calculations. The Journal of Physical Chemistry. 1994 Jun;98(23):5867-77.

10. Alia J. Chemical Reasoning Based on an Invariance Property: Bond and Lone Pair Pictures in Quantum Structural Formulas. Symmetry. 2010 Jul 23;2(3):1559-90.

11. Alia JD. Molecular Structural Formulas as One-Electron Density and Hamiltonian Operators: The VIF Method Extended. The Journal of Physical Chemistry A. 2007 Mar;111(12):2307-18.

12. This figure was depicted from the arguments of reference 13 and 14.

13. Borkar S, Sztaray B, Bodi A. Dissociative photoionization mechanism of methanol isotopologues $\left(\mathrm{CH}_{3} \mathrm{OH}, \mathrm{CD}_{3} \mathrm{OH}, \mathrm{CH}_{3} \mathrm{OD}\right.$ and $\left.\mathrm{CD}_{3} \mathrm{OD}\right)$ by iPEPICO: energetics, statistical and non-statistical kinetics and isotope effects. Phys. Chem. Chem. Phys. 2011; 13:13009.

14. Thapa B, Schlegel HB. Molecular Dynamics of Methanol Monocation $\left(\mathrm{CH}_{3} \mathrm{OH}^{+}\right)$in Strong Laser Fields. Journal of Physical Chemistry A. 2014; 118:10, 1769. 
15. Mass spectra of "methanol, ethanol, formaldehyde, formic acid, NB, DNB, TNB and TNT" molecules, in NISTchemistry web book, NIST Standard Reference Database Number 69. National Institute of Standards and Technology, Gaithersburg, MD, 20899, (http://webbook.nist.gov)

16. Blanksby SJ, Ellison GB. Bond Dissociation Energies of Organic Molecules. Accounts of Chemical Research. 2003 Apr;36(4):255-63.

17. Stephen AD, Kumaradhas P, Pawar RB. Charge Density Distribution, Electrostatic Properties, and Impact Sensitivity of the High Energetic Molecule TNB: A Theoretical Charge Density Study. Propellants, Explosives, Pyrotechnics. 2011 Apr;36(2):168-74.

18. Ellena J, Goeta AE, Howard JAK, Punte G. Role of the Hydrogen Bonds in Nitroanilines Aggregation: Charge Density Study of 2-Methyl-5-nitroaniline. The Journal of Physical Chemistry A. 2001 Sep;105(38):8696-708.

19. SRINIVASAN P, MAHESHWARI K, JOTHI M, Kumaradhas P. Charge Density Distribution, Electrostatic Properties and Sensitivity of the Highly Energetic Molecule 2,4,6-Trinitro-1,3,5triazine: A Theoretical Study. Central European Journal of Energetic Materials. 2012;9(1):59-76. URL: http://yadda.icm.edu.pl/yadda/element/bwmeta1.element.baztech-article-BAT1-00410077/c/httpwww_wydawnictwa_ipo_waw_plcejemvol-9-1-2012srinivasan.pdf.

20. Stephen AD, Pawar RB, Kumaradhas P. Exploring the bond topological properties and the charge depletion-impact sensitivity relationship of high energetic TNT molecule via theoretical charge density analysis. Journal of Molecular Structure: THEOCHEM. 2010 Nov;959(1-3):55-61.

21. Mass spectra of "dodecane" and "methanone, diphenyl-, oxime" molecules, in NISTchemistry web book, NIST Standard Reference Database Number 69. National Institute of Standards and Technology, Gaithersburg, MD, 20899, (http://webbook.nist.gov)

22. Tuncel EF, Berkay S, Berna O, Nebahat D. Synthesis, characterization and biological activity of a new long-chain imine ligand and some transition metal complexes in solvent-free conditions. Main Group Chemistry. 2012;(3):217-222.

23. Smith P, Dimmock J, Turner W. Mass Spectrometry of Some Substituted 2Benzylidenecyclohexanone Oximes. Can J Chem. 1973;51(9):1471-5. DOI: 10.1139/v73-221.

24. Smith PJ, Dimmock JR, Turner WA. Mass Spectrometry of Some Substituted 2Benzylidenecyclohexanones and 2,6-bis-Benzylidenecyclohexanones. Canadian Journal of Chemistry. 1973 May;51(9):1458-70. DOI: 10.1139/v73-220.

25. Smith PJ, Dimmock JR, Taylor WG. Mass Spectrometry of some Nuclear Substituted Styryl Ketones. Canadian Journal of Chemistry. 1972 Mar 15;50(6):871-9. DOI: 10.1139/v72-136. 


\section{Türkçe Öz ve Anahtar Kelimeler Kütle Spektrometrisinin Sistematikleri Üzerine: Yeni bir Graf- Teorik Yöntem}

Berkay Sütay

Öz: Kütle spektrometrisinin (MS) sistematik artalanı Değerlik Etkileşim Formülü teorisinin etkin bir şekilde kullanılmasıyla ortaya konmuştur. Yeni graf teorik yöntem, saf bir kuantum mekanik araştırma olarak geliştirilmiştir ve kütle spektrometrisinin arkasındaki kuantum mekanik sistematikleri aydınlatmak için bir seri molekül ve birleşiklere uygulanmıştır. Kimya ve fizikteki topolojik indisler ve graf teorik yöntemler bu yeni yöntemin çarpıcı özellikleri olup pek çok molekül ve birleşiğin kütle spektrumlarına uygulanmıştır (artık kullanılmaz hale gelmiş parçalanma prosedürlerinden dolayı). Bu esaslı topolojik indisler, moleküllerin kütle spektrumları üzerinde hızlı tahminler yapma ve kararlar alma olanağı vermesi için kullanılmıştır. Kütle Spektrometrisinin çarpıcı yönlerinden biri olarak, pek çok molekülün temel parçalanma yolları tamamen teorik bir yolla incelenmiş ve a priori bozunma ürünleri tahmin edilmiştir. Sistematik teori incelememizin ışığında ortaya konmuştur ve hangi etkileşimlerin diğerleri arasında yumuşak tabiatlı olduğu öğrenildikten sonra çok miktarda kalitatif bilgi elde edilmiştir.

The results are of general validity in comparison with the experimental data.

Sonuçlar, deneysel verilerle kıyaslandığında genel olarak geçerli bulunmuştur.

Anahtar kelimeler: Kütle spektroskopisi; değerlik etkileşim formülü; elektron çarpma iyonlaştırması; topoloji; graf teorisi.

Gönderme: 19 Ağustos 2016. İkinci tur: 20 Ekim 2016. Kabul: .09 Kasım 2016 
Sütay, JOTCSA. 2017;4(1):179-196.

RESEARCH ARTICLE 